Journal of Loss Prevention in the Process Industry, 26(2):290-294, 2013.

Preprint, available on line 3 April 2011. see journal for final version

http://dx.doi.org/10.1016/j.jlp.2011.03.007

\title{
Experimental Investigation of Spark Ignition Energy in Kerosene, Hexane, and Hydrogen
}

\author{
S. P. M. Bane ${ }^{\mathrm{a}, *}$, J. L. Ziegler ${ }^{\mathrm{a}}$, P. A. Boettcher ${ }^{\mathrm{a}}$, S. A. Coronel $^{\mathrm{a}}$, J. E. Shepherd ${ }^{\mathrm{a}}$ \\ ${ }^{a}$ California Institute of Technology \\ 1200 E. California Blvd., MC 205-45 \\ Pasadena, California 91125, USA
}

\begin{abstract}
Quantifying the risk of accidental ignition of flammable mixtures is extremely important in industry and aviation safety. The concept of a minimum ignition energy (MIE), obtained using a capacitive spark discharge ignition source, has traditionally formed the basis for determining the hazard posed by fuels. While extensive tabulations of historical MIE data exist, there has been little work done on ignition of realistic industrial and aviation fuels, such as gasoline or kerosene. In the current work, spark ignition tests are performed in a gaseous kerosene-air mixture with a liquid fuel temperature of $60^{\circ} \mathrm{C}$ and a fixed spark gap of $3.3 \mathrm{~mm}$. The required ignition energy was examined, and a range of spark energies over which there is a probability of ignition is identified and compared with previous test results in Jet A (aviation kerosene). The kerosene results are also compared with ignition test results obtained in previous work for traditional hydrogen-based surrogate mixtures used in safety testing as well as two hexane-air mixtures. Additionally, the statistical nature of spark ignition is discussed.
\end{abstract}

Keywords: gas explosion, spark ignition, minimum ignition energy, hydrogen, hexane, kerosene

\footnotetext{
${ }^{*}$ Corresponding author

Sally P. M. Bane

California Institute of Technology

1200 E. California Blvd. Mail Code 205-45

Pasadena, CA 91125

ph: +1 (626) 395-3163

fax: +1 (626) 395-2900

email: sallym@caltech.edu
} 


\section{Introduction}

Determining the risks posed by combustion hazards is a topic of tremendous importance in industry and aviation. In combustion science, the concept of minimum ignition energy (MIE) has traditionally formed the basis for studying and quantifying ignition hazards of fuels. The viewpoint is that a flammable mixture has a specific ignition energy threshold corresponding to the MIE, and ignition sources with energy below this threshold will never ignite the mixture and sources with energy above the MIE will always cause ignition. Standard test methods for determining the MIE have been developed which use a capacitive spark discharge as the ignition source (Babrauskas, 2003, Magison, 1990), and the ASTM developed standard E582 based on these methods (ASTM, 2009). The MIE is determined from the energy stored in a capacitor at a known voltage that is then discharged through a specified fixed electrode gap. The pioneering work using this test method to determine MIE values was performed at the Bureau of Mines in the 1940s by Guest, Blanc, Lewis, and von Elbe (Lewis and von Elbe, 1961). They obtained a large amount of MIE data for many different fuels, and this data is extensively cited in the literature, ignition handbooks, and explosion test methods (Babrauskas, 2003, Magison, 1990). Following the work at the Bureau of Mines, other researchers have conducted MIE testing using methods similar to those employed by Lewis and von Elbe and found comparable results. Calcote et al. (1952) used the same methods to determine MIE values for various pure hydrocarbon fuels up to $\mathrm{C}_{10}$, and Metzler $(1952,1953)$ and Moorhouse et al. (1974) studied ignition energies of pure $\mathrm{C}_{1}$ to $\mathrm{C}_{7}$ hydrocarbons. More recently, Ono et al. (2007) obtained MIE values for hydrogen-air mixtures.

In industry and aviation, however, the actual threat is often ignition of more complex fuels such as gasoline or kerosene, fuels that are blends of 100-200 hydrocarbons with a broad range of carbon atoms per molecule. In safety testing and certification, simpler fuels are often used instead; for example, the standards used in aviation safety certification recommend a very lean hydrogen-based test mixture (ARP, 2005). However, little experimental work has been done on investigating the ignition energies of very lean hydrogen mixtures and actual civil or aviation kerosene (Jet A). Nestor (1967) performed experiments to determine the flammability limits of Jet A in air at atmospheric

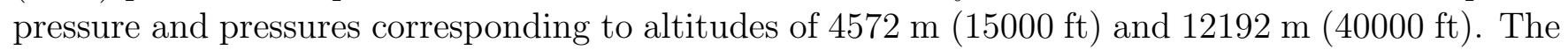
flammability limits were given in terms of the temperature range within which there is sufficient vapor pressure of fuel for ignition. Additionally, Nestor (1967) investigated ignition of Jet A spray droplets. Ott (1970) also studied flammability of aviation kerosene (JP-8) and the effect of fuel slosh on the flammability limits. Following the crash of Trans World Airlines Flight 800 in 1996 , a series of studies were performed by Shepherd et al. (1999) and Lee and Shepherd (2000) on the flammability and ignition energy of Jet A. The minimum ignition energy of Jet A was found to vary between $100 \mathrm{~J}$ for a fuel/air temperature of $25^{\circ} \mathrm{C}$ to $40 \mathrm{~mJ}$ at $55^{\circ} \mathrm{C}$. Despite these previous efforts, we are still lacking a comprehensive database of ignition energy data with quantified uncertainty for use in safety engineering and assessment. 
In our previous work on spark ignition, we examined ignition near the MIE of lean hydrogenbased mixtures used in aviation testing (Bane et al., 2010) and two hexane-air mixtures (Bane, 2010, Bane and Shepherd, 2009) to compare the relative risk of explosion. Instead of obtaining a single threshold minimum ignition energy, ignition was found to be probabilistic in nature at low spark energies. The statistical nature of ignition has been observed by previous authors (Lee and Shepherd, 2000, Moorhouse et al., 1974) and the viewpoint of ignition as a statistical phenomenon has recently been proposed in the aviation industry (FAA, 1994). Therefore, the hydrogen and hexane ignition data was analyzed using statistical methods to obtain probability distributions for ignition versus the spark energy, energy density (energy per unit spark length), and spark charge. The energy density and spark charge were found to be more suitable measures of the risk of ignition than a single spark energy.

In the current work, ignition of kerosene by short duration $(<100 \mathrm{~ns})$, low energy $(<10 \mathrm{~mJ})$ capacitive sparks is examined experimentally. The resulting ignition energies required for kerosene at $60^{\circ} \mathrm{C}$ and atmospheric pressure are compared with the results for the lean hydrogen and hexane test mixtures previously studied.

\section{Materials and Methods}

\subsection{Experimental Setup}

The spark ignition experiments were performed in a closed, cylindrical pressure vessel approximately $22 \mathrm{~L}$ in volume. The vessel was constructed out of stainless steel to minimize corrosion, and the inside of the vessel was carefully machined to eliminate crevices. The vessel has four large flanges and various ports for plumbing connections. Two parallel flanges were used to mount the electrodes for the low-energy spark ignition system developed for this work. The ignition system is described in detail in Bane et al. (2010) and Bane (2010). Extensive efforts were made to develop an ignition system to generate sparks characteristic of accidental electrostatic discharge and to quantify the standard discharge energy. Windows were mounted in the other two parallel flanges for visualization. A remotely controlled plumbing system was used to evacuate the vessel and to fill gases. The gas pressure was measured using a piezoresistive pressure transducer with the output displayed by a National Instruments LabVIEW virtual instrument to a precision of $0.01 \mathrm{kPa}$. An exhaust line was installed to circulate fresh air through the vessel. A variable-speed fan mixer, mounted near the top of the vessel, was used to mix the gases to ensure homogeneous composition.

To perform experiments using fuels which have low vapor pressures at room temperature, a heating system was designed and constructed to heat the vessel to temperatures up to approximately $150^{\circ} \mathrm{C}$. Flexible silicone heaters were mounted on the surfaces of the vessel and flanges and divided into four zones, each with a separate temperature controller. The heaters were powered using a

3-phase, 208 V, 50 A power supply. The vessel was insulated using fiberglass jackets to minimize radiant heat loss. 
Three separate methods were used to determine whether or not ignition occurred. The first indication of ignition and subsequent flame propagation was the pressure rise detected by the pressure transducer. A second method used for detecting ignition was measuring the temperature rise using a K-type thermocouple inside the vessel. Finally, the spark kernel and flame propagation was visualized using a schlieren system and high-speed video camera.

\subsection{Experimental Methods}

When performing experiments using gaseous fuels at room temperature, as done in the previous hydrogen and hexane testing (Bane, 2010, Bane and Shepherd, 2009, Bane et al., 2010), the vessel was first evacuated and then filled with gases using the method of partial pressures. However, when using a fuel with low vapor pressure such as kerosene, the experimental method is significantly more complicated. The desired fuel mass loading, which is the mass of liquid fuel divided by the vessel volume, was first chosen to determine the volume of kerosene to be put in the vessel. Then, with the vessel at room temperature, the kerosene was poured into the vessel, forming a liquid pool at the bottom. The combustion vessel was then sealed and heated. The heating system zone at the bottom of the vessel was set to the desired temperature of the fuel $\left(60^{\circ} \mathrm{C}\right.$ in the present work), and the other three heating zones were set approximately $20^{\circ} \mathrm{C}$ higher to prevent fuel condensation. The fan mixer was used throughout the entire heating process. Once the desired fuel temperature was reached and all condensation on the windows had evaporated, the final gas temperature and pressure were recorded. There was no a method to fix the final pressure after heating, but the amount of fuel vapor was kept as constant as possible by precisely controlling the liquid fuel temperature to within 1 degree of $60^{\circ} \mathrm{C}$ for all the tests. This fuel temperature resulted in a final gas pressure of $104.0 \pm 1.0 \mathrm{kPa}$. A spark was then initiated, and if ignition occurred, air was circulated through the vessel before removing the vessel lid to clean the electrodes, insulators, and windows. Even if ignition did not occur, the vessel lid had to be removed before the next test to sand and dry the electrode surfaces. After three ignition events, the kerosene was pumped out, the inside of the vessel was thoroughly cleaned, and fresh kerosene was added.

\section{Results and Discussion}

In the present work, ignition of $1-\mathrm{K}$ kerosene at $60^{\circ} \mathrm{C}$ and atmospheric pressure was examined. The temperature was chosen to produce enough fuel vapor so that the fuel-air mixture was well above the lower flammability limit of aviation kerosene as given by Nestor (1967). Also, it slightly exceeds the maximum temperature $\left(56.1^{\circ} \mathrm{C}\right)$ investigated by Shepherd et al. (1999). As in Shepherd et al. (1999), the spark gap in these tests was fixed at $3.3 \mathrm{~mm}$, approximately the optimum gap size for Jet A ignition. Using variable vacuum capacitors with capacitances of approximately 3 to $300 \mathrm{pF}$ and breakdown voltages between 10 and $12 \mathrm{kV}$, the spark energy could be varied between approximately 0.4 to $300 \mu \mathrm{J}$. The mass of liquid fuel was found to have little effect on the minimum 
ignition energy for mass loadings greater than $35 \mathrm{~kg} / \mathrm{m}^{3}$ (Shepherd et al., 1999), so in the present tests a mass loading of approximately $50 \mathrm{~kg} / \mathrm{m}^{3}$ (1.4 L of kerosene) was used.

The first test was performed with a spark energy of well above the MIE results of Shepherd et al. (1999) to confirm that the mixture was flammable and to visualize the flame propagation. Schlieren images of the kerosene ignition are shown in Figure 1 and the pressure trace is shown in Figure 2. The flame propagation velocity can be estimated from the schlieren video by measuring the rate of horizontal growth of the flame. The flame radius was measured every $0.50 \mathrm{~ms}$ from $6.5 \mathrm{~ms}$ after the spark (when the flame was approximately spherical) to $16.5 \mathrm{~ms}$. The propagation velocity of the flame front was then estimated to be approximately $58 \mathrm{~cm} / \mathrm{s}$, given a laminar burning velocity $s_{u}$ on the order of $10 \mathrm{~cm} / \mathrm{s}$. This value is comparable to flame speeds of hexane mixtures close to the flammability limit. Although the burning velocity is the same order of magnitude, it is definitively lower than the value of $s_{u}$ obtained for Jet A by Shepherd et al. (1999), who obtained effective burning speeds between approximately $30 \mathrm{~cm} / \mathrm{s}$ and $50 \mathrm{~cm} / \mathrm{s}$ for Jet A at $56^{\circ} \mathrm{C}$. The values in Shepherd et al. (1997) were obtained using the " $t^{3}$ " analysis method; therefore the difference between those burning speeds and the present result is most likely due to the difference in estimation methods. The peak pressure obtained during the kerosene combustion was approximately 6.5 bar, higher than the approximately 4 bar peak pressure reported by Shepherd et al. (1999).
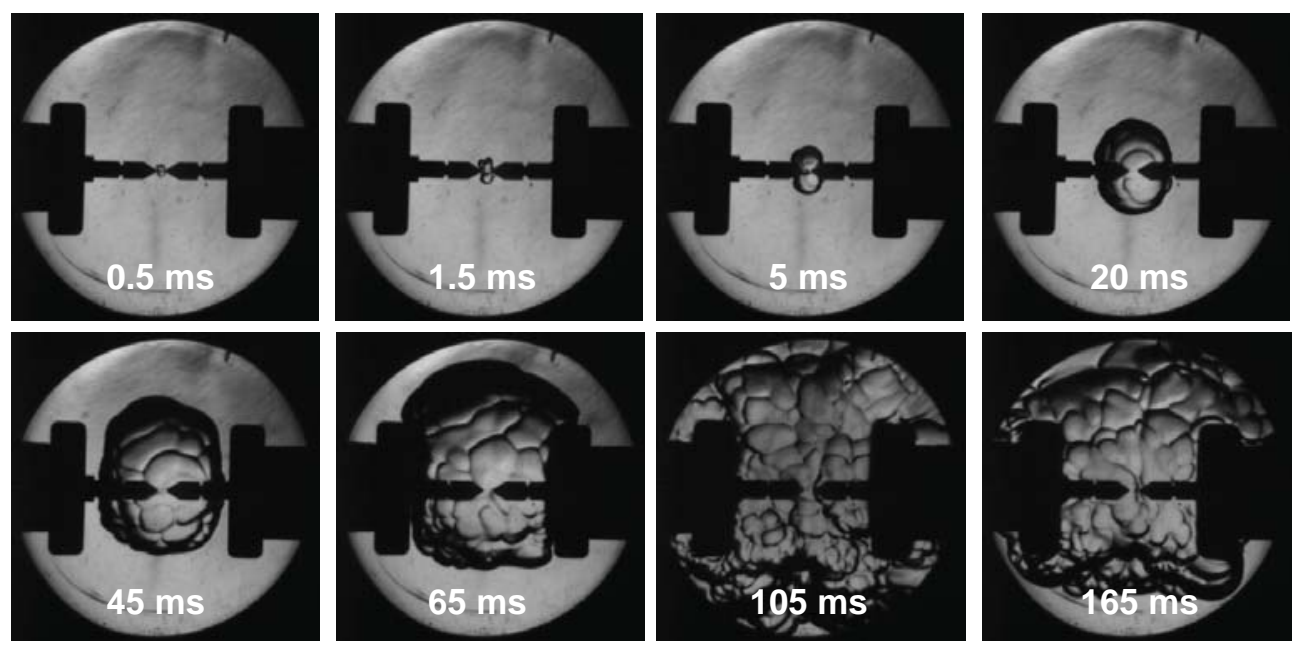

Figure 1: Images from high-speed schlieren visualization of ignition and flame propagation in kerosene-air at $60^{\circ} \mathrm{C}$.

A set of 12 spark ignition tests were performed with spark energies ranging from $0.45 \mathrm{~mJ}$ to $2.2 \mathrm{~mJ}$, shown in Figure 3. The range of spark energy where the ignition cases overlap with the non-ignition cases is highlighted in gray. The lowest spark energy that caused ignition was $0.65 \mathrm{~mJ}$, 


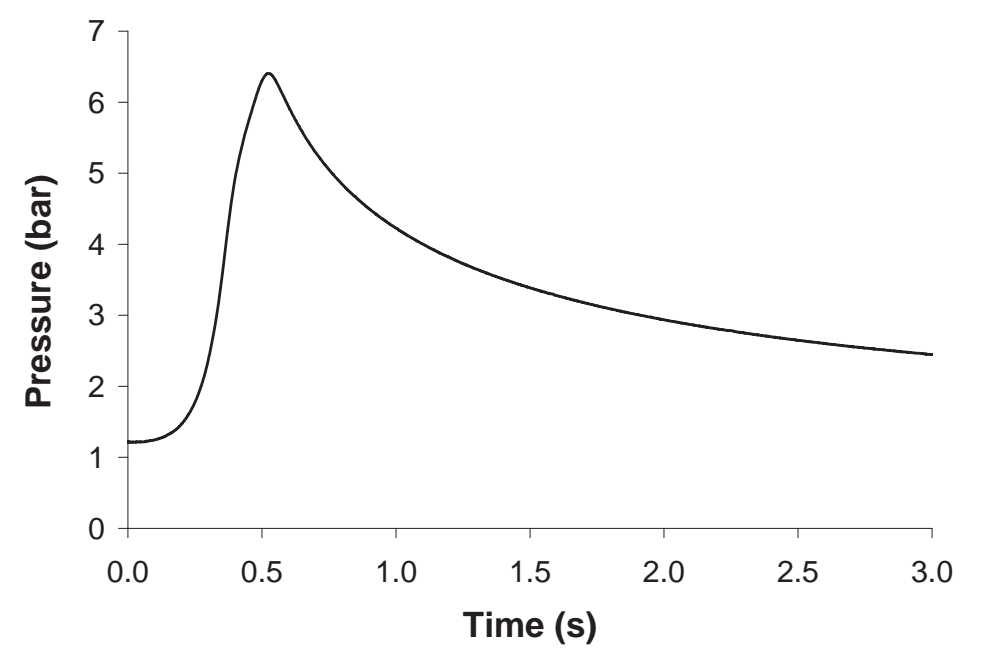

Figure 2: Pressure versus time inside the vessel following ignition of kerosene at $60^{\circ} \mathrm{C}$.

and the highest spark energy with no ignition was $1.75 \mathrm{~mJ}$. These results demonstrate the statistical nature of spark ignition near the minimum ignition energy threshold. There is a finite probability of ignition in the data overlap region rather a single well-defined "go" or "no go" threshold. This is consistent with our previous work on spark ignition of hydrogen and hexane (Bane, 2010, Bane and Shepherd, 2009, Bane et al., 2010). In previous work, the minimum ignition energy was found for Jet A at atmospheric pressure (Lee and Shepherd, 2000) and at 0.585 bar (Shepherd et al., 1999). The highest fuel temperature tested at atmospheric pressure was $52^{\circ} \mathrm{C}$, and the lowest spark energy to cause ignition was approximately $40 \mathrm{~mJ}$. This value is nearly two orders of magnitude larger than the lowest ignition energy in the present work $(0.65 \mathrm{~mJ})$. However, the fuel vapor pressure scales exponentially with increasing temperature, so raising the temperature from $52^{\circ} \mathrm{C}$ to $60^{\circ} \mathrm{C}$ would be expected to cause a decrease in the ignition energy. For the tests at reduced pressure $(0.585$ bar), the highest fuel temperature tested was $56.1^{\circ} \mathrm{C}$ and the lowest ignition energy was found to be approximately $2 \mathrm{~mJ}$. The ignition energy for those conditions was 20 times lower than for the atmospheric pressure, $52^{\circ} \mathrm{C}$ case due to both the increase in temperature and the increased fuel/air ratio at the lower pressure. These new ignition test results indicate that kerosene can be ignited with lower spark energies than previously thought possible, and that the overall minimum ignition energy will occur for liquid fuel temperatures of $60^{\circ} \mathrm{C}$ or above.

The kerosene ignition results can also be compared with the results of previous ignition tests in hydrogen and hexane (Bane, 2010, Bane and Shepherd, 2009, Bane et al., 2010). In previous work, spark ignition tests were performed in the lean hydrogen test mixture recommended by the SAE for aviation safety certification, $5 \% \mathrm{H}_{2}, 12 \% \mathrm{O}_{2}, 83 \% \mathrm{Ar}$ (ARP, 2005). Experiments were also 


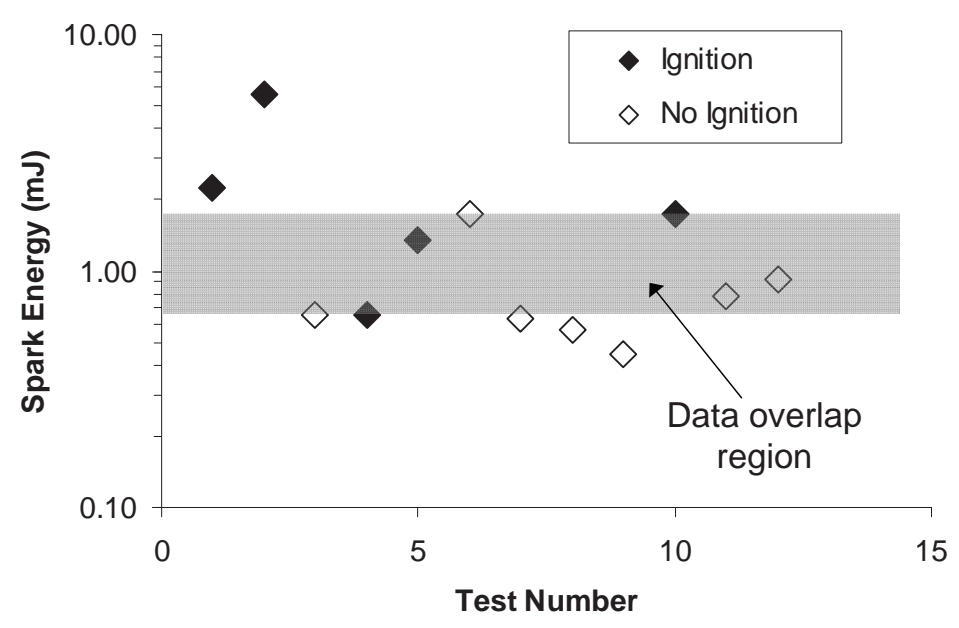

Figure 3: Data points from the 12 spark ignition tests performed in kerosene-air at $60^{\circ} \mathrm{C}$. The data overlap region is shown in gray.

conducted using mixtures with 6 and $7 \% \mathrm{H}_{2}\left(12 \% \mathrm{O}_{2}\right)$ to investigate the effect of small changes in the fuel concentration on the required ignition energies. The test results were analyzed using the statistical methods described in Bane et al. (2010), where a model was proposed for the probability distribution for ignition versus spark energy. These probability distributions for the hydrogen test mixtures are shown in Figure 4 along with the data points from the tests in kerosene. The plot shows that two of the successful ignition tests in kerosene had spark energies comparable to the ignition energies for the $5 \% \mathrm{H}_{2}$ mixture. This is an important result because the $5 \% \mathrm{H}_{2}$ mixture was chosen by the SAE for aviation testing under the assumption that it is significantly more sensitive than Jet A under all conditions. However, the present results demonstrate that for some conditions, kerosene can be more sensitive, and hence easier to ignite, than the standard hydrogen test mixture.

In previous work, ignition tests were also performed in the $6 \% \mathrm{H}_{2}$ mixture and in two hexane-air mixtures: a stoichiometric hexane-air mixture, and a rich $(\phi=1.7)$ hexane-air mixture. The rich mixture was chosen because, according to historical MIE data, it is the hexane-air mixture with the lowest MIE value (Lewis and von Elbe, 1961). In these prior tests, both the spark energy and spark length were varied to derive probability distributions for ignition versus spark energy density (energy per unit length), shown in Figure 5. To compare the ignition energy results in kerosene to the results of the previuos work, the spark energies must be divided by the spark length $(3.3 \mathrm{~mm}$ for all tests) to obtain the energy density. The lowest spark energy that gave an ignition, $0.65 \mathrm{~mJ}$, has an energy density of $197 \mu \mathrm{J} / \mathrm{mm}$; the highest spark energy with no ignition, $1.75 \mathrm{~mJ}$, has an energy density of $530 \mu \mathrm{J} / \mathrm{mm}$. This region of spark energy densities is also shown in Figure 5 in gray. The 


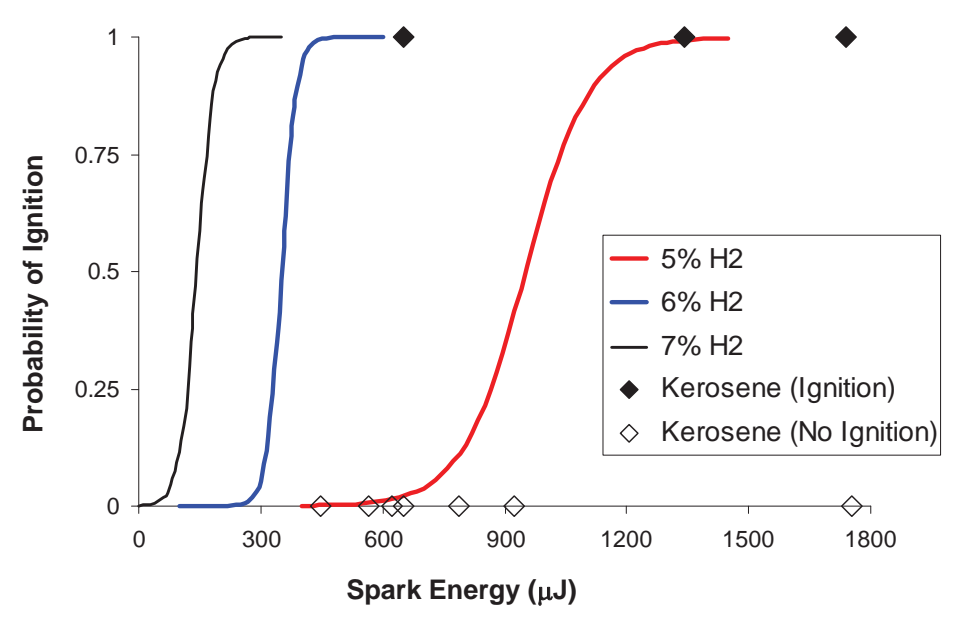

Figure 4: Ignition probability distributions developed from analyzing test data for the $5 \% \mathrm{H}_{2}$ mixture recommended by the SAE for aviation testing and mixtures with 6 and $7 \% \mathrm{H}_{2}$ (Bane et al., 2010). The data from the present kerosene ignition tests are shown for comparison.

results suggest that the kerosene-air mixture at $60^{\circ} \mathrm{C}$ is comparable to the rich hexane-air mixture in terms of ignition energy density, as the data overlap region for the kerosene lies at approximately the center of the probability distribution for the $\phi=1.7$ hexane mixture. Further work is needed to fully investigate the comparison between kerosene and hexane, including spark ignition tests in kerosene with varying spark lengths.

\section{Conclusions}

In previous work (Bane, 2010, Bane et al., 2010), we had examined spark ignition of hydrogen and hexane mixtures near the minimum ignition energy threshold using a very low-energy capacitive spark discharge system. The same spark ignition system was used in the present work to perform ignition tests in kerosene-air with a fuel temperature of $60^{\circ} \mathrm{C}$, mass loading of $50 \mathrm{~kg} / \mathrm{m}^{3}$, and a fixed spark gap of $3.3 \mathrm{~mm}$. The "go" (ignition) and "no go" (no ignition) data points were found to overlap, indicating variability in the data, which is in concordance with previous work (Lee and Shepherd, 2000) showing the statistical nature of Jet A ignition. The fuel temperature exceeded the maximum temperatures of 52 and $56.1^{\circ} \mathrm{C}$ used in the prior work, and significantly lower ignition energies were found, with ignition occurring with a spark energy as low as $0.65 \mathrm{~mJ}$. This is smaller than the MIE that we found previously for the $5 \%$ hydrogen test mixture recommended for aviation safety testing. Fortunately, the recommended test practices of ARP5416 permit richer mixtures and also require validation with a $200 \mu \mathrm{J}$ spark. Additionally, the ignition energy density (spark 


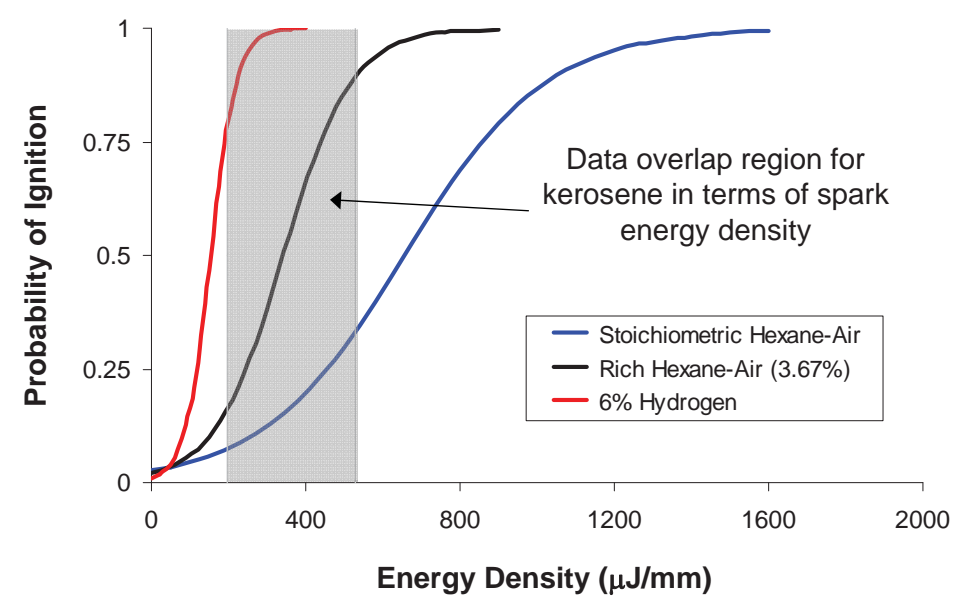

Figure 5: Probability distributions for ignition versus spark energy density for the $6 \%$ hydrogen test mixture and two hexane-air mixtures (Bane, 2010). Shown in gray is the data overlap region for kerosene at $60^{\circ} \mathrm{C}$ in terms of the energy density (spark energy divided by the $3.3 \mathrm{~mm}$ spark length).

energy divided by the spark length) of kerosene was found to be comparable to the ignition energy densities of the hexane mixture with the lowest MIE $(\phi=1.7)$. Therefore, the results of the present work indicate that the sensitivity of kerosene must be re-examined, and the variability of spark ignition must also be considered when assessing risk in industry and aviation and designing safety standards.

\section{Acknowledgements}

This work was carried out in the Explosion Dynamics Laboratory of the California Institute of Technology and was supported by The Boeing Company through a Strategic Research and Development Relationship Agreement CT-BA-GTA-1.

\section{References}

ARP, 2005. Aerospace Recommended Practice Aircraft Lightning Test Methods. SAE International, ARP5416.

ASTM, 2009. Standard Test Method for Minimum Ignition Energy and Quenching Distance in Gaseous Mixtures. American Society for Testing and Materials International, E582-07. 
Babrauskas, V., 2003. Ignition Handbook: Principles and Applications to Fire Safety Engineering, Fire Investigation, Risk Management and Forensic Science. Fire Science Publishers, Issaquah, WA.

Bane, S. P. M., 2010. Spark ignition: Experimental and numerical investigation with application to aviation safety. Ph.D. thesis, California Institute of Technology.

Bane, S. P. M., Shepherd, J. E., 2009. Statistical analysis of electrostatic spark ignition, Fall Meeting of the Western States Section of the Combustion Institute, University of California Irvine, Irvine, CA, paper 09F-64.

Bane, S. P. M., Shepherd, J. E., Kwon, E., Day, A. C., 2010. Statistical analysis of electrostatic spark ignition of lean H2/O2/Ar mixtures. Int. J. Hydrog. Energy doi:10.1016/j.ijhydene.2010.05.082.

Calcote, H. F., C. A. Gregory, J., Barnett, C. M., Gilmer, R. B., 1952. Spark ignition effect of molecular structure. Ind. Eng. Chem. 44, 2656-2662.

FAA, 1994. Aircraft fuel system lightning protection design and qualification test procedures development. Final Report DOT/FAA/CT-94/74, U.S. Dept. of Transportation Federal Aviation Administration.

Lee, J. J., Shepherd, J. E., 2000. Spark energy measurements in Jet A part II. GALCIT report FM 99-7, Graduate Aerospace Laboratories, California Institute of Technology.

Lewis, B., von Elbe, G., 1961. Combustion, Flames and Explosions of Gases. Academic Press, New York.

Magison, E. C., 1990. Electrical Equipment in Hazardous Locations, 3rd Edition. Instrument Society of America.

Metzler, A. J., 1952. Minimum ignition energies of six pure hydrocarbon fuels of the C2 and C6 series. Research Memorandum E52F27, NACA.

Metzler, A. J., 1953. Minimum ignition energies of 12 pure fuels at atmospheric and reduced pressure. Research Memorandum E53H31, NACA.

Moorhouse, J., Williams, A., Maddison, T. E., 1974. An investigation of the minimum ignition energies of some C1 to C7 hydrocarbons. Combust. Flame 23, 203-213.

Nestor, L., 1967. Investigation of turbine fuel flammability within aircraft fuel tanks. Final report DS-67-7, Naval Air Propulsion Test Center, Philadelphia, PA. 
Ono, R., Masaharu, N., Fujiwara, S., Horiguchi, S., Oda, T., 2007. Minimum ignition energy of hydrogen-air mixture: Effects of humidity and spark duration. J. Electrost. 65, 87-93.

Ott, E., 1970. Effects of fuel slosh and vibration on the flammability hazards of hydrocarbon turbine fuels within aircraft fuel tanks. Tech. Rep. AFAPL-TR-70-65, Fire Protection Branch of the Fuels and Lubrication Division, Wright-Patterson Air Force Base, Ohio.

Shepherd, J. E., Krok, C., Lee, J. J., 1999. Spark ignition energy measurements in Jet A. GALCIT report FM97-9, Graduate Aerospace Laboratories, California Institute of Technology.

Shepherd, J. E., Krok, J. C., Lee, J. J., 1997. Jet A explosion experiments: laboratory testing. GALCIT report FM97-5, Graduate Aerospace Laboratories, California Institute of Technology. 